\title{
Roughening of Copper (100) at Elevated CO Pressure: Cu Adatom and Cluster Formation Enable CO Dissociation
}

\author{
Matteo Roiaz, ${ }^{\dagger}$ Laura Falivene, ${ }^{\ddagger}$ Christoph Rameshan, ${ }^{\dagger}$ Luigi Cavallo, ${ }^{\ddagger}$ Sergey M. Kozlov, \\ and Günther Rupprechter* ${ }^{*}+0$ \\ ${ }^{\dagger}$ Institute of Materials Chemistry, Technische Universität Wien, 1060 Vienna, Austria \\ ${ }^{\ddagger}$ KAUST Catalysis Center, Kind Abdullah University of Science and Technology (KAUST), Thuwal 23955-6900, Saudi Arabia \\ Supporting Information
}

ABSTRACT: Carbon monoxide participates in many coppercatalyzed reactions, which makes CO-induced structural changes of $\mathrm{Cu}$ catalysts key for important industrial processes. We have studied the interaction of carbon monoxide with the $\mathrm{Cu}(100)$ single crystal termination at 120,200 , and $300 \mathrm{~K}$ by means of low-energy electron diffraction (LEED), temperature-programmed desorption (TPD), X-ray photoelectron spectroscopy (XPS), polarizationmodulation infrared reflection absorption spectroscopy (PMIRAS), and density functional theory (DFT) calculations. The absorption band of CO $\left(2082-2112 \mathrm{~cm}^{-1}\right)$ at elevated gas pressure (up to $5 \mathrm{mbar}$ ) and at $200 / 300 \mathrm{~K}$ was found at a higher wavenumber than the characteristic band of the $c(2 \times 2) \mathrm{CO}$ structure and was consistent with $\mathrm{CO}$ adsorbed on low-coordinated

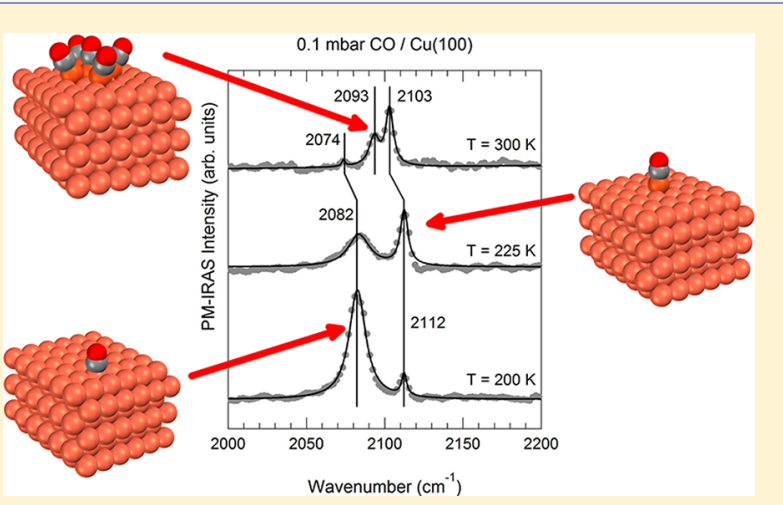
$\mathrm{Cu}$ atoms. The combined PM-IRAS/DFT analysis revealed that exposure to $\mathrm{CO}$ induced surface roughening through the formation of $\mathrm{Cu}$ adatoms and clusters on the (100) terraces. The roughened surface seemed surprisingly active for $\mathrm{CO}$ dissociation, which indicates its unique catalytic properties.

\section{INTRODUCTION}

Both carbon monoxide and copper are key players in the industrial synthesis of methanol. The latter is produced from a mixture of $\mathrm{CO}, \mathrm{CO}_{2}$, and $\mathrm{H}_{2}$, typically over a (nominal) $\mathrm{Cu}$ / $\mathrm{ZnO} / \mathrm{Al}_{2} \mathrm{O}_{3}$ catalyst at $510-530 \mathrm{~K}$ and $50-100$ bar, in a process developed by ICI in $1966 .{ }^{1}$ It is commonly agreed on that $\mathrm{CO}_{2}$ is the main carbon source of methanol ${ }^{2}$ even though methanol synthesis from $\mathrm{CO}$ on $\mathrm{Cu} / \mathrm{ZnO}$ is also feasible. ${ }^{3}$ Moreover, density functional theory (DFT) suggested that the reaction may proceed through a $\mathrm{CO}$ intermediate on $\mathrm{Cu}$ / $\mathrm{CeO}_{2}$ catalysts. ${ }^{4} \mathrm{Cu}$ is known to be mainly responsible for the catalytic activity; however, a fine-tuning by potential $\mathrm{Zn}$ alloying and by the $\mathrm{ZnO}$ support is crucial. ${ }^{5-7}$ The exact role of $\mathrm{CO}$ in methanol synthesis is still debated, and particularly, its interaction with $\mathrm{Cu}$ at elevated pressure deserves further attention. $\mathrm{CO}$ interaction with $\mathrm{Cu}$ is also important for the electrochemical $\mathrm{CO}_{2}$ reduction to $\mathrm{CO}$ and further reduction to valuable $\mathrm{C}_{2}$ products catalyzed by $\mathrm{Cu}^{8-11} \mathrm{~A}$ promising approach toward these and other complex industrially important processes is via well-defined model studies. ${ }^{12-15}$

The adsorption of $\mathrm{CO}$ on the (100) single crystal surface of $\mathrm{Cu}$ in UHV at cryogenic temperature has been well studied by various experimental techniques, such as infrared reflection absorption spectroscopy (IRAS), ${ }^{16-19}$ photoemission spectroscopy (PES), ${ }^{20-23}$ low-energy electron diffraction (LEED), ${ }^{24-26}$ pump-probe, ${ }^{27-29}$ and high-resolution electron energy loss spectroscopy (HREELS). ${ }^{26}$ However, there are discrepancies among the few experimental studies of $\mathrm{CO}$ adsorption at room (and higher) temperature and higher gas pressure, which may originate from significant variations in experimental conditions. For example, Taylor and Pritchard ${ }^{30}$ reported a single IR-absorption band at $2071 \mathrm{~cm}^{-1}$ assigned to $\mathrm{CO}$ adsorbed on top of $\mathrm{Cu}$ atoms, upon exposing $\mathrm{Cu}(100)$ at $300 \mathrm{~K}$ to 0.44 mbar CO. Quite differently, Truong et al. ${ }^{31}$ reported one prominent band at $2086 \mathrm{~cm}^{-1}$ and a shoulder between 2095 and $2110 \mathrm{~cm}^{-1}$, when exposing $\mathrm{Cu}(100)$ at 265 $\mathrm{K}$ to $0.57 \mathrm{mbar} \mathrm{CO}$. The first feature was assigned to $\mathrm{CO}$ adsorbed on top sites, whereas the second one was ascribed to $\mathrm{CO}$ adsorbed at stepped sites.

In these early studies, the adsorbate-induced reconstruction of the $\mathrm{Cu}$ substrate ${ }^{32}$ was not considered, despite being known for other metals. For example, $\mathrm{CO}$ induces restructuring of stepped platinum surfaces ${ }^{33}$ and supported metal nanoparticles, as shown by electron microscopy, ${ }^{34}$ infrared spectroscopy, ${ }^{35}$ or scanning tunneling microscopy (STM). ${ }^{36}$ Very recent high-pressure (HP-) STM and near ambient pressure Xray photoelectron spectroscopy (NAP-XPS) investigations of $\mathrm{Cu}(111),{ }^{37} \mathrm{Cu}(110),{ }^{38}$ and $\mathrm{Cu}(100)^{39}$ single crystals by

Special Issue: Hans-Joachim Freund and Joachim Sauer Festschrift

Received: August 7, 2018

Revised: October 11, 2018

Published: October 23, 2018 
Salmeron and co-workers revealed reconstruction of $\mathrm{Cu}$ surfaces upon exposure to mbar pressure of $\mathrm{CO}$ at $300 \mathrm{~K}$. On all single crystal surfaces the formation of $\mathrm{Cu}$ clusters was observed with, e.g., 3, 5, or 19 atoms, as well as of three atom wide (elongated) clusters. For $\mathrm{Cu}(110)$, IRAS experiments were performed at 0.02 Torr, with adsorbed $\mathrm{CO}$ detected at $2099 \mathrm{~cm}^{-1}$ (CO adsorbed at the end atom (coordination number $=6$ ) of short (few $\mathrm{nm}$ ) linear $\mathrm{Cu}$ clusters), and at $2084 \mathrm{~cm}^{-1}$ (CO adsorbed in the middle $(\mathrm{CN}=7)$ of linear clusters). ${ }^{38}$

Herein, we present a combined LEED/temperatureprogrammed desorption (TPD)/XPS/PM-IRAS/DFT study of $\mathrm{CO} / \mathrm{Cu}(100)$, including both in situ and ex situ studies of the (ongoing) surface roughening of $\mathrm{CO}$ at room temperature and near-atmospheric pressure, employing a dedicated UHVhigh-pressure cell combination. ${ }^{40,41}$ Special caution was taken to guarantee a clean sample environment (gold-coated cell) and purified gases. Apart from $\mathrm{Cu}$ cluster formation, which may be important for methanol synthesis by maintaining a rough active surface and counteracting sintering, the modified surface also exhibited unexpected activity for $\mathrm{CO}$ dissociation.

\section{EXPERIMENTAL AND COMPUTATIONAL DETAILS}

All experiments were performed in a custom-built UHV chamber, which has been previously described in detail. ${ }^{40,41}$ It has been successfully used for various investigations such as $\mathrm{CO}$ adsorption/hydrogenation and methanol decomposition/ oxidation on (sputtered) $\mathrm{Pd}(111)$ and supported Pd nanoparticles, ${ }^{42-45}$ methanol steam re-forming on bimetallic $\mathrm{PdZn}$ model catalyst, ${ }^{46-50}$ and $\mathrm{CO}$ adsorption on Ir. $^{51}$ In brief, the chamber comprises two parts, a classical UHV chamber and a UHV-compatible high-pressure cell ("Rupprechter-design" $\left.{ }^{40,41}\right)$. The upper UHV section allows sample preparation and characterization by standard surface science techniques such as ion bombardment and annealing, XPS, LEED, and TPD. Afterward, the sample can be transferred under UHV to the lower section, a gold-coated spectroscopic highpressure cell, in which polarization-modulation IRAS (PMIRAS) experiments can be performed in a pressure range from UHV to 1 bar. All mbar gas pressure exposures herein were performed in the well-baked PM-IRAS high-pressure cell. The gold-coated walls counteract the adsorption of potential contaminations that could be subsequently replaced from the walls. Room temperature UHV transfer of a $\mathrm{Cu}(100)$ sample to the high-pressure cell, its exposure to UHV for $1 \mathrm{~h}$, and transfer back to the UHV section did not affect the TPD spectrum of $\mathrm{CO}$, with only minute amounts of "transfer carbon" detected in the XPS spectrum of the sample (see below).

For the current study, a disk-shaped ( $8 \mathrm{~mm}$ diameter, $2 \mathrm{~mm}$ thickness) $5 \mathrm{~N}$-purity copper (100) single crystal (roughness and orientation accuracies better than $30 \mathrm{~nm}$ and $1^{\circ}$, respectively) was purchased from MaTeck. It was mounted via a tantalum wire cage on two molybdenum rods, which allowed resistive heating and cooling by liquid $\mathrm{N}_{2}$. The temperature was monitored by a chromel-alumel thermocouple spot-welded to the back of the sample. The $\mathrm{Cu}$ single crystal was cleaned by repeated cycles of $\mathrm{Ar}^{+}$bombardment for $15 \mathrm{~min}\left(1 \times 10^{-5} \mathrm{mbar}, 1.5 \mathrm{kV}, 3.6 \times 10^{-6} \mathrm{~A}\right.$ sputter current $)$ and annealing to $800 \mathrm{~K}$ for $5 \mathrm{~min}$. When required, the sample was annealed to $600 \mathrm{~K}$ in $1 \times 10^{-7}$ mbar oxygen before sputtering, to remove carbon contamination. For other highpressure cell designs, refer to refs 52-54.
Surface order and cleanliness of the sample were confirmed by LEED (SPECS ErLEED 150) and XPS, respectively. X-ray radiation from a nonmonochromated dual anode $\mathrm{Mg} / \mathrm{Al}$ source (SPECS XR 50) was impinging on the sample at the angle of $55^{\circ}$ with respect to the surface normal, and photoelectrons were detected at normal emission by a hemispherical energy analyzer (SPECS PHOIBOS 150). For the TPD experiments, the sample was heated with a linear temperature ramp of $1 \mathrm{~K} \mathrm{~s}^{-1}$ (Eurotherm 3216 PID controller). The desorption products were detected by a differentially pumped mass spectrometer (Pfeiffer PrismaPlus 220) through a nozzle closely facing the sample, in order to minimize the detection of species desorbing from the sample mount and to prevent readsorption of molecules. Research grade CO (99.997\%) from an aluminum lecture bottle (Messer Austria) was admitted to the experimental chamber only after passing through a carbonyl purifying cartridge (Entegris GateKeeper $300 \mathrm{KF}$ ) and a cold trap filled with a liquid $\mathrm{N}_{2} /$ ethanol mixture at $170 \mathrm{~K}$. PM-IRAS (Bruker IFS 66v/S FTIR spectrometer, liquid $\mathrm{N}_{2}$-cooled $\mathrm{HgCdTe}$ detector, HINDS PEM-90 ZnSe photoelastic modulator) was used to measure the vibrational properties of adsorbed CO species. Using polarization-modulation enables differentiation between surface adsorbate and gas-phase contributions and acquisition of surface vibrational spectra from UHV to atmospheric pressure. ${ }^{55-58}$ The PM-IRAS spectrum of the clean sample, prior to admitting $\mathrm{CO}$ to the spectroscopic cell, was used in all cases to normalize the spectra (not shown). PM-IRAS spectra were fitted with multiple Lorentzian lines, and XPS spectra were fitted with the CasaXPS software after linear-background subtraction. The peaks were fitted with mixed Gaussian/ Lorentzian line shapes, and fwhm and peak positions were left unconstrained.

The VASP software was used to perform periodic calculations with the rPBE exchange correlation functional, which is particularly suitable for studies of adsorption on metal surfaces. The eigenstates of the valence electrons were calculated using plane-wave basis sets with a cutoff of 400 eV. First-order Methfessel-Paxton smearing of $0.1 \mathrm{eV}$ was applied to the occupation numbers. The presence of core electrons was accounted for via the projector augmented wave technique. Monkhorst-Pack mesh of k-points $(5 \times 5 \times 1)$ was used to sample the reciprocal space in the slab calculations. Geometry optimization was performed until the forces on all atoms were less than $0.2 \mathrm{eV} \mathrm{nm}{ }^{-1}$. Vibrational frequencies were calculated in the harmonic approximation by displacing $\mathrm{C}$ and $\mathrm{O}$ atoms by $\pm 3 \mathrm{pm}$ in all three Cartesian directions, which yielded values within $3 \mathrm{~cm}^{-1}$ from those obtained using density functional perturbation theory. The surfaces were modeled using a 6 layer $p(4 \times 4)$ periodic slab hexagonal supercell of $1275 \times 1275 \mathrm{pm}^{2}$. The separation between adjacent slabs exceeded $1 \mathrm{~nm}$.

The average adsorption free energies of the $\mathrm{CO}$ species were calculated as follows:

$$
G_{\text {ads }}=\left(G\left[N \times \frac{\mathrm{CO}}{\text { substrate }}\right]-G[\text { substrate }]-N \times G\left[\mathrm{CO}_{\mathrm{gas}}\right]\right) / N
$$

In this equation, $G[N \times \mathrm{CO} /$ substrate $]$ is the energy of the substrate (i.e., surface, $\mathrm{Cu}_{1} / \mathrm{Cu}(100), \mathrm{Cu}_{5} / \mathrm{Cu}(100)$, kinked surface) with $N$ of $\mathrm{CO}$ molecule(s) adsorbed, $G$ [substrate] is the energy of the substrate, and $G\left[\mathrm{CO}_{\text {gas }}\right]$ is the energy of the gas-phase $\mathrm{CO}$. For the $\mathrm{Cu}_{5} / \mathrm{Cu}(100)$, on which $1-5 \mathrm{CO}$ 
molecules are adsorbed, the differential adsorption energies were calculated as follows:

$$
\begin{aligned}
G_{\mathrm{ads}}^{\mathrm{diff}}= & G[N \times \mathrm{CO} / \text { substrate }]-G[(N-1) \\
& \times \mathrm{CO} / \text { substrate }]-G\left[\mathrm{CO}_{\mathrm{gas}}\right]
\end{aligned}
$$

Finally, the formation free energies of $\mathrm{Cu}_{x}(x=1, \ldots, 5)$ clusters were calculated as follows:

$$
\begin{aligned}
G_{\text {form }}= & G\left[N \times \mathrm{CO} / \mathrm{Cu}_{x} / \mathrm{Cu}(100)\right]-G[\mathrm{Cu}(100)] \\
& -x \times G[\mathrm{Cu}]-N \times G\left[\mathrm{CO}_{\text {gas }}\right]
\end{aligned}
$$

Here, $G\left[N \times \mathrm{CO} / \mathrm{Cu}_{x} / \mathrm{Cu}(100)\right]$ is the free energy of the substrate with $N$ adsorbed $\mathrm{CO}$ molecule(s), $G[\mathrm{Cu}(100)]$ is the energy of the bare surface, $G[\mathrm{Cu}]$ is the energy of the single $\mathrm{Cu}$ atom in $\mathrm{Cu}$ bulk, and $\mathrm{G}\left[\mathrm{CO}_{\text {gas }}\right]$ is the free energy of the gas-phase $\mathrm{CO}$. The free energy calculations were done at $T=$ $200 \mathrm{~K}$ and included zero-point energy corrections. In particular, we used the ideal gas approximation and $p(\mathrm{CO})=$ $0.1 \mathrm{mbar}$ to evaluate the free energy of gas-phase CO. With these definitions, negative adsorption free energies and cluster formation free energies correspond to exothermic processes.

\section{RESULTS AND DISCUSSION}

3.1. CO Adsorption on $\mathrm{Cu}(100)$ under UHV Conditions. Figure 1 displays LEED results. After cleaning the $\mathrm{Cu}$
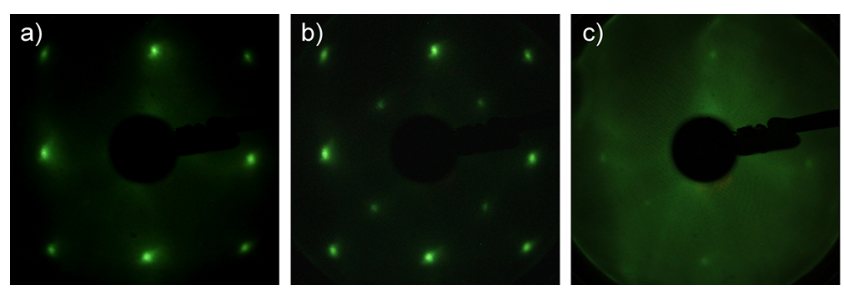

Figure 1. LEED patterns of (a) the clean and ordered as-prepared $\mathrm{Cu}(100)$ surface at room temperature, $(\mathrm{b})$ the $c(2 \times 2) \mathrm{CO}$ overlayer at $120 \mathrm{~K}$ after $\sim 40 \mathrm{~L} \mathrm{CO}$ exposure, and (c) the $\mathrm{Cu}$ surface disordered after $40 \mathrm{~min}$ exposure to $1 \mathrm{mbar} \mathrm{CO}$ at room temperature. The beam energy was $157 \mathrm{eV}$.

single crystal prior to each experiment, a LEED pattern characteristic of the (100) surface was observed (Figure 1a), and no contaminants were detected by XPS (i.e., in the $\mathrm{O}$ 1s and $\mathrm{C} 1 \mathrm{~s}$ binding energy (BE) regions, Figure $\mathrm{S} 1)$. Thereafter, the low-temperature adsorption of $\mathrm{CO}$ on $\mathrm{Cu}(100)$ was addressed, and several benchmark experiments were performed by LEED, XPS, TPD, and PM-IRAS. In all these experiments, the adsorbate layer was prepared by cooling the clean copper single crystal from 300 to $120 \mathrm{~K}$ in $1 \times 10^{-7} \mathrm{mbar}$ CO. The cooling took approximately $9 \mathrm{~min}$; therefore, the sample was exposed to $\sim 40 \mathrm{~L}\left(1 \mathrm{~L}=1 \times 10^{-6}\right.$ Torr s $)$ of carbon monoxide. After evacuation, a sharp $c(2 \times 2)$ LEED pattern, corresponding to $0.5 \mathrm{ML} \mathrm{CO}$ coverage, was observed (Figure $1 b)$.

The $c(2 \times 2) \mathrm{CO}$ overlayer formed on the $\mathrm{Cu}$ surface was also examined by XPS, and the spectra for $\mathrm{O} 1 \mathrm{~s}$ and $\mathrm{C} 1 \mathrm{~s}$ binding energy regions are shown in Figure 2a. The left side of Figure 2 displays the $\mathrm{O} 1 \mathrm{~s}$ difference spectra (between adsorbate-covered and bare surfaces) to exclude contributions of the high-kinetic-energy tail of the Cu LMM Auger triplet. In both $\mathrm{O} 1 \mathrm{~s}$ and (on the right side) $\mathrm{C} 1 \mathrm{~s}$ spectra, along with the two main ("adiabatic") peaks at 533.2 and $286.2 \mathrm{eV}$,

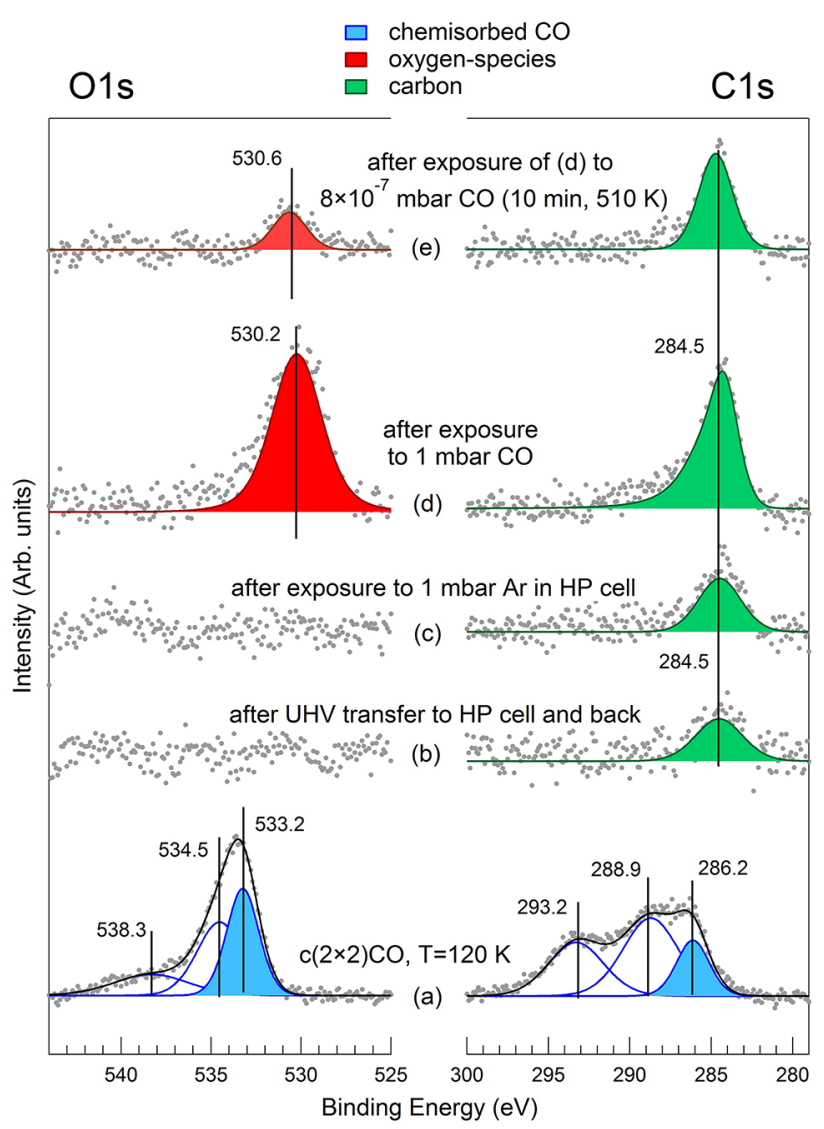

Figure 2. XPS spectra of the $\mathrm{O} 1 \mathrm{~s}$ and $\mathrm{C} 1 \mathrm{~s}$ binding energy regions of (a) the $c(2 \times 2) \mathrm{CO}$ overlayer at $120 \mathrm{~K}$ after $\sim 40 \mathrm{~L}$ CO exposure; (b) the clean $\mathrm{Cu}(100)$ surface after UHV transfer to the HP cell (keeping the sample there for $60 \mathrm{~min}$ ), and UHV transfer back; (c) the clean $\mathrm{Cu}(100)$ surface after UHV transfer to the HP cell (keeping the sample there in $1 \mathrm{mbar}$ Ar for $40 \mathrm{~min}$ ), and UHV transfer back; (d) the same after exposure to $1 \mathrm{mbar} \mathrm{CO}$ at $300 \mathrm{~K}$ for $40 \mathrm{~min}$ and evacuation; and (e) after exposing the surface of (d) to $8 \times 10^{-7} \mathrm{mbar}$ $\mathrm{CO}$ at $510 \mathrm{~K}$ for $10 \mathrm{~min}$. All spectra acquired in UHV: (a) at $120 \mathrm{~K}$ and $(\mathrm{b}-\mathrm{e})$ at $300 \mathrm{~K}$.

respectively, also satellite features appeared at higher $\mathrm{BE}$ upon CO adsorption (Figure 2a). Such "giant satellites" are well-known to be characteristic of weakly chemisorbed CO. ${ }^{20-23,59}$ Taking advantage of the known CO coverage of $0.5 \mathrm{ML}$, confirmed by LEED, we have used the XPS peak area for quantitative calibration, required to determine the coverage of oxygen and carbon species in subsequent XPS experiments.

TPD results are collected in Figure 3. Before examining the $c(2 \times 2) \mathrm{CO}$ overlayer on the $\mathrm{Cu}$ surface by TPD, we have acquired a background TPD in order to determine the amount of potential contaminants adsorbing from the residual gas (base pressure $2 \times 10^{-10} \mathrm{mbar}$ ), which appeared to be negligible $\sim 0.01 \mathrm{ML}$ traces of water and CO (see Supporting Information Figure S2). As shown in Figure 3a, CO of the $c(2$ $\times 2$ ) overlayer has a peak maximum at $170 \mathrm{~K}$. Desorption below $140 \mathrm{~K}$ is due to $\mathrm{CO}$ desorbing from the Ta heating wires, as observed previously using the same experimental setup. $^{60}$ On the basis of the Redhead approximation ${ }^{61}$ and assuming a desorption rate prefactor of $1 \times 10^{13} \mathrm{~s}^{-1}$, the activation energy of desorption is estimated to be $44 \mathrm{~kJ} \mathrm{~mol}^{-1}$ for the main peak in Figure 3a, in good agreement with the value reported for $\mathrm{CO}$ on $\mathrm{Cu}(100) .{ }^{62}$ We further observed that the adsorption was fully reversible, so that the TPD spectrum 


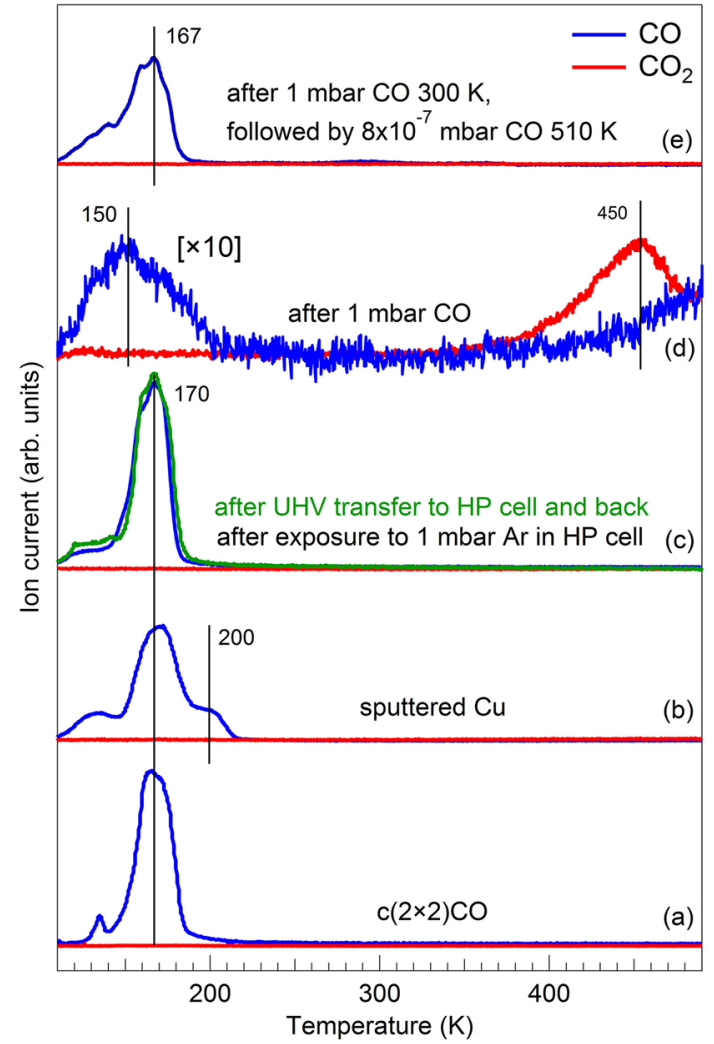

Figure 3. All TPD spectra were taken after cooling the $\mathrm{Cu}(100)$ sample from 300 to $120 \mathrm{~K}$ in $1 \times 10^{-7} \mathrm{mbar} \mathrm{CO}$, i.e., $\sim 40 \mathrm{~L} \mathrm{CO}$ exposure: (a) $\mathrm{CO}$ desorption from the $c(2 \times 2) \mathrm{CO}$ overlayer prepared on the well-ordered $\mathrm{Cu}(100)$ surface and $(\mathrm{b})$ on the ionbombarded defective $\mathrm{Cu}$ surface. (c) TPD experiments performed after transferring the clean sample in UHV to the HP cell (keeping the sample there in UHV or $1 \mathrm{mbar} \mathrm{Ar}$ at $300 \mathrm{~K}$ ) and UHV transfer back. Spectrum d was taken after $\mathrm{Cu}(100)$ exposure to $1 \mathrm{mbar} \mathrm{CO}$ at $300 \mathrm{~K}$ for 40 min with $\mathrm{CO}$ and $\mathrm{CO}_{2}$ signals enlarged 10 times. The TPD spectrum in part e was acquired after exposing the surface after treatment described in part $\mathrm{d}$ to $8 \times 10^{-7} \mathrm{mbar} \mathrm{CO}$ at $510 \mathrm{~K}$ for 10 $\min$.

of the $c(2 \times 2) \mathrm{CO}$ structure could be repeated several times (see Supporting Information Figure S2). We also performed a
TPD experiment after preparing a CO adsorbate layer on the sputtered, defect-rich, $\mathrm{Cu}(100)$ surface. As shown in Figure $3 \mathrm{~b}$, an additional desorption feature appeared at $200 \mathrm{~K}$, due to $\mathrm{CO}$ desorbing from defect sites created by ion bombardment. An activation energy of desorption of $53 \mathrm{~kJ} \mathrm{~mol}^{-1}$ was calculated for the defect sites. Note that also for the defect-rich surface all $\mathrm{CO}$ desorbed below $220 \mathrm{~K}$.

The low-temperature $\mathrm{CO}$ adsorption on $\mathrm{Cu}(100)$ at $1 \times$ $10^{-6}$ mbar CO pressure was also investigated by PM-IRAS (Figure 4), and the band at $2082 \mathrm{~cm}^{-1}$ at $120 \mathrm{~K}$ was attributed to the $c(2 \times 2) \mathrm{CO}$ overlayer. When the sample was heated to more than $140 \mathrm{~K}$, the CO coverage decreased and the combined effect of reduced dipole-dipole and chemical interaction red-shifted the band, as previously discussed ${ }^{18,19,63}$ (see Figure $4 \mathrm{a}$ ). At $160 \mathrm{~K}$, the band position at $\sim 2072 \mathrm{~cm}^{-1}$ was in line with the data by Ryberg. ${ }^{19}$ Heating to higher temperature $(180 \mathrm{~K})$ led to a further red-shift to $2060 \mathrm{~cm}^{-1}$. Above $170 \mathrm{~K}$ (the TPD desorption maximum in Figure 3a), the peak became very small.

In turn, PM-IRAS spectra of CO adsorbed at low temperature on sputtered $\mathrm{Cu}(100)$ showed a (weaker) band at $2082 \mathrm{~cm}^{-1}$, assigned to $\mathrm{CO}$ adsorbed on well-ordered terraces, and a shoulder at $2092 \mathrm{~cm}^{-1}$ (Figure 4b).

The latter higher-frequency PM-IRAS peak, apparently related to the sputtering, was conclusively assigned on the basis of DFT simulations (Figure 5 and Table 1 ). The same holds for $\mathrm{CO}$ adsorbed on various sites and $\mathrm{Cu}$ clusters. The selection of the sites was based on previous STM observations of surface roughening by the Salmeron group. ${ }^{39}$ The absolute values of experimental and calculated $\mathrm{CO}$ vibrational wavenumbers, $\tilde{\nu}$, differ due to unaccounted anharmonic contributions to vibrational frequencies in the simulations and inherent approximations of the RPBE exchange-correlation functional. In order to facilitate comparison of experimental values and computational results, we consider the difference between $\mathrm{CO}$ vibrational frequencies on a given site $X$ and on ordered $\mathrm{Cu}(100), \Delta \tilde{\nu}[X]=\tilde{\nu}[X]-\tilde{\nu}[\mathrm{Cu}(100)]$. For example, the PMIRAS spectrum of $\mathrm{CO}$ adsorbed on sputtered $\mathrm{Cu}(100)$ exhibits a shoulder at $\Delta \tilde{\nu}=2092-2082 \mathrm{~cm}^{-1}=10 \mathrm{~cm}^{-1}$, which compares well to simulation of $\mathrm{CO}$ adsorbed on step edges, $\Delta \tilde{\nu}$ $=2019-2011 \mathrm{~cm}^{-1}=8 \mathrm{~cm}^{-1}$. The difference between calculated $\mathrm{CO}$ adsorption energies on step and terrace sites,
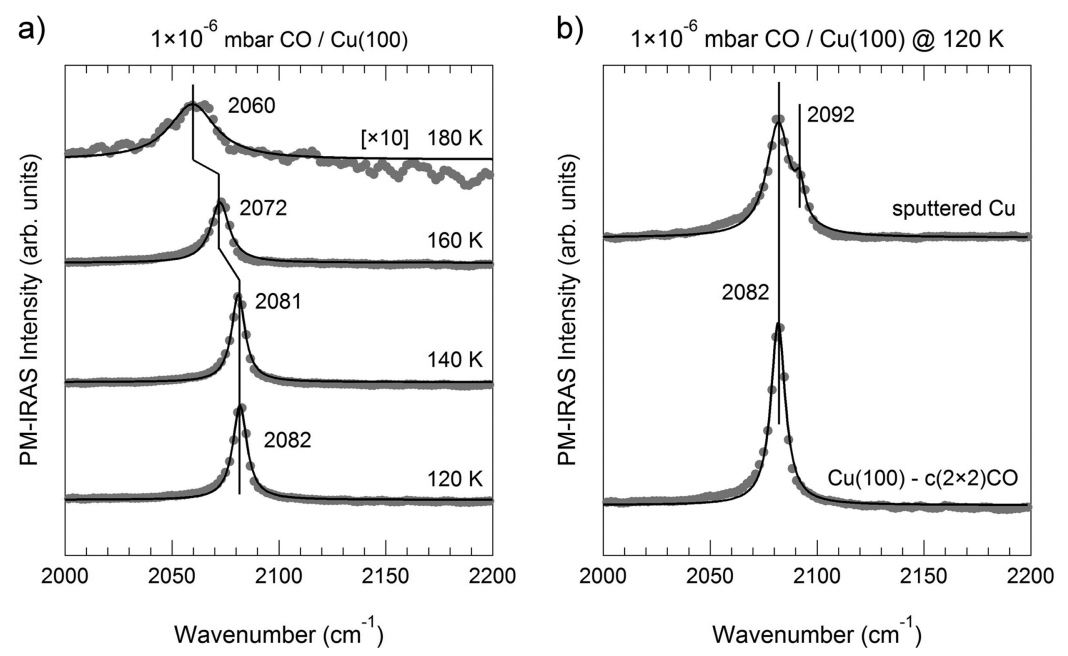

Figure 4. PM-IRAS results of (a) the as-prepared well-ordered $\mathrm{Cu}(100)$ surface and (b) the sputtered $\mathrm{Cu}$ surface, cooled from 300 to $120 \mathrm{~K}$ in $1 \times$ $10^{-6}$ mbar CO. 

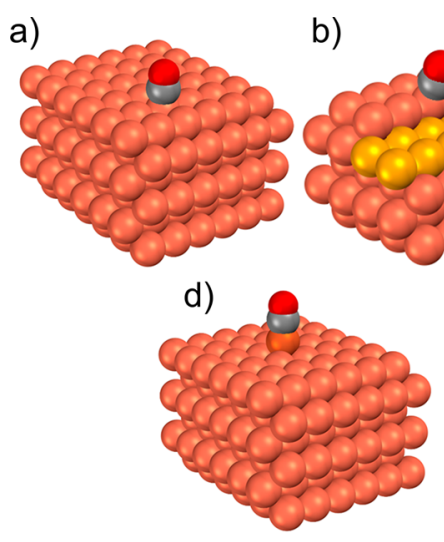

b)

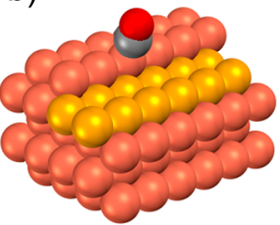

e)

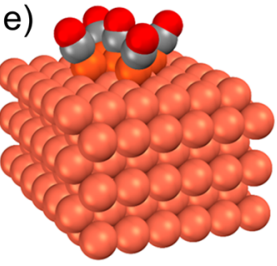

C)

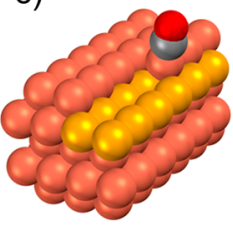

$41-30=11 \mathrm{~kJ} \mathrm{~mol}^{-1}$, also agrees well with the respective difference obtained from TPD analysis, 53-44 $=9 \mathrm{~kJ} \mathrm{~mol}^{-1}$. The adsorption of $\mathrm{CO}$ on low-coordinated $\mathrm{Cu}$ sites is also in line with adsorption studies on polycrystalline $\mathrm{Cu}$ films $\left(\sim 2105 \mathrm{~cm}^{-1}\right.$ or $\left.2090-2093 \mathrm{~cm}^{-1}\right) .^{30,64-68}$

3.2. Adsorption of $\mathrm{CO}$ on $\mathrm{Cu}(100)$ at mbar Pressure. After collecting UHV benchmark data at low temperature, $\mathrm{CO}$ adsorption at elevated temperature and at near atmospheric pressure was addressed (Figure 6). Because of the well-known issue of nickel or iron contamination when working with $\mathrm{CO}$ in this pressure regime (originating from the gas storage/ manifold hardware ${ }^{56}$ ), special cleaning precautions were made (see the Experimental and Computational Details section). Indications of a contaminated $\mathrm{Cu}$ surface would include unusual low-wavenumber bands for adsorbed $\mathrm{CO}$ in IRAS (from 2020 to $2060 \mathrm{~cm}^{-1}$ ), ${ }^{69} \mathrm{CO}$ desorption features at about $360 \mathrm{~K}$ in TPD, and detection of the $\mathrm{Fe}$ or $\mathrm{Ni} 2 \mathrm{p}$ doublet in postexposure XPS analysis. ${ }^{2,30}$ None of this was observed, ruling out $\mathrm{Fe}$ or Ni contamination.

Two bands at 2082 and $2112 \mathrm{~cm}^{-1}$ were measured by PMIRAS in $0.1 \mathrm{mbar} \mathrm{CO}$ at $200 \mathrm{~K}$ (Figure $6 \mathrm{a}$ ). The first is due to the $c(2 \times 2) \mathrm{CO}$ overlayer on $\mathrm{Cu}(100)$ terraces. On the basis of DFT results (Figure 5 and Table 1 ), the second band is attributed to $\mathrm{CO}$ adsorbed on $\mathrm{Cu}_{1}$ adatoms on the $\mathrm{Cu}(100)$ surface, whose calculated $\Delta \tilde{\nu}_{\mathrm{DFT}}=35 \mathrm{~cm}^{-1}$ agrees well with the experimental blue-shift of $\Delta \tilde{\nu}_{\exp }=30 \mathrm{~cm}^{-1}$. The formation of such $\mathrm{CO} / \mathrm{Cu}_{1}$ is only slightly endothermic, $G_{\text {form }}=4 \mathrm{~kJ} \mathrm{~mol}^{-1}$, which suggests that such complexes may form through the detachment of $\mathrm{Cu}_{1}$ atoms from kink sites upon $\mathrm{CO}$ adsorption, and then they may migrate over the surface (Figure 7). Such detachment would be favored by higher $\mathrm{CO}$ pressure (which explains the absence of this band in spectra in Figure 4) and higher temperature (which explains the higher band intensity at 225 and $300 \mathrm{~K}$ in Figure 6a). Previously, these bands were assigned to $\mathrm{CO}$ adsorption on terraces and defects, but no rationalization of the variation of their relative intensity upon increasing the $\mathrm{CO}$ pressure from $1.3 \times 10^{-5}$ to $0.57 \mathrm{mbar}$ at $265 \mathrm{~K}$ was provided. ${ }^{31}$

At higher temperature, not only can more $\mathrm{Cu}_{1} \mathrm{CO}$ complexes detach from the steps, but their diffusion rate is also expected to increase with a possible coalescence into $\mathrm{Cu}$ stability of this structure is confirmed by significant differential adsorption energy of the 5th CO molecule, $G_{\mathrm{ads}}^{\text {diff }}=-36 \mathrm{~kJ} \mathrm{~mol}^{-1}$ (Table S1). ${ }^{e}$ Three calculated frequencies at 2032, 2030, and 2029 $\mathrm{cm}^{-1}$ are combined in one peak (see Table S2 for further details).

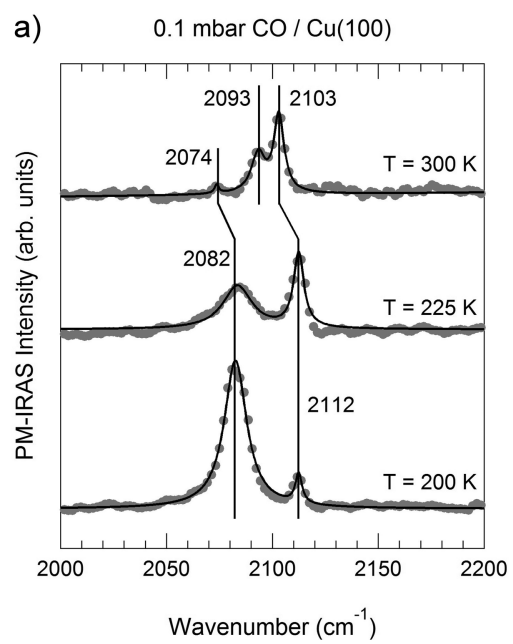

b)

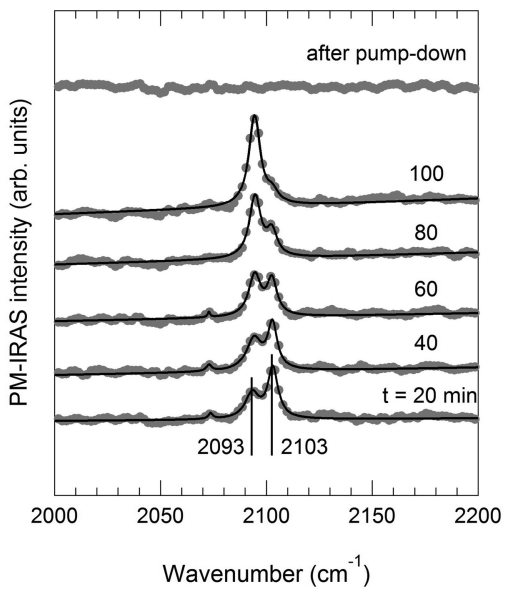

Figure 6. (a) PM-IRAS spectra on “ $\mathrm{Cu}(100)$ " recorded in $0.1 \mathrm{mbar} \mathrm{CO}$ at 200, 225, and $300 \mathrm{~K}$. The features at 2082 and $2112 \mathrm{~cm}^{-1}$ are assigned to $\mathrm{CO}$ adsorbed on terraces and $\mathrm{CO} / \mathrm{Cu}_{1}$ complexes, respectively. (b) Time evolution of PM-IRAS spectra recorded in $0.1 \mathrm{mbar} \mathrm{CO}$ at $300 \mathrm{~K}$. The features at 2093 and $2103 \mathrm{~cm}^{-1}$ are assigned to $\mathrm{CO}$ adsorbed at $\mathrm{Cu}$ clusters and adatoms, respectively. 

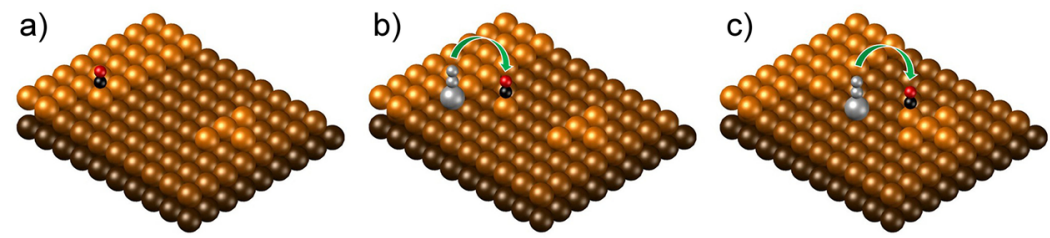

Figure 7. Schematic $\mathrm{CO}$-induced surface roughening: (a) $\mathrm{CO}$ on a kink atom with coordination number $\mathrm{CN}=6$, (b) on an adatom $\mathrm{Cu} \mathrm{u}_{1}$ with $\mathrm{CN}=$ 4 , and (c) on top of a $\mathrm{Cu}_{5}$ cluster atom with $\mathrm{CN}=5$. According to the proposed mechanism for cluster formation, a $\mathrm{CO}$ molecule adsorbed on a kink $\mathrm{Cu}$ atom lowers its binding energy (a) and forms a $\mathrm{Cu}_{1} \mathrm{CO}$ complex, which is mobile on the surface (b). The latter can then coalesce with other adatoms forming a $\mathrm{Cu}$ cluster (c).
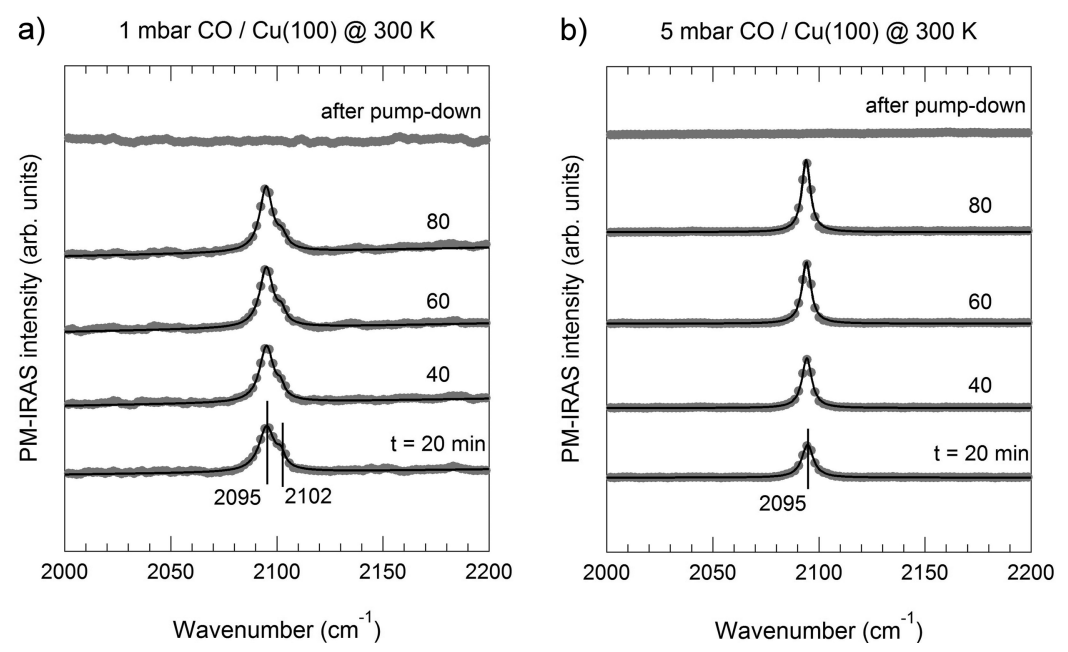

Figure 8. Time evolution of PM-IRAS spectra of " $\mathrm{Cu}(100)$ ” recorded in (a) $1 \mathrm{mbar} \mathrm{CO}$ and (b) $5 \mathrm{mbar} \mathrm{CO}$ at $300 \mathrm{~K}$.

clusters via Ostwald ripening. ${ }^{70}$ When the temperature was increased to $300 \mathrm{~K}$, the band of $\mathrm{CO}$ covering the $\mathrm{Cu}(100)$ terraces became barely noticeable and red-shifted to 2074 $\mathrm{cm}^{-1}$ (Figure $6 \mathrm{a}$ ). The peak characteristic of $\mathrm{CO} / \mathrm{Cu}_{1}$ was also red-shifted by almost the same magnitude to $2103 \mathrm{~cm}^{-1}$ at 300 K.

In addition, a new band appeared at $2093 \mathrm{~cm}^{-1}$, blue-shifted $\left(\Delta \tilde{\nu}_{\exp }=2093-2074\right)$ by $19 \mathrm{~cm}^{-1}$. This scenario is in reasonable agreement with $\mathrm{CO}$ adsorbed on $\mathrm{Cu}_{5}$ clusters formed by coalescence of $\mathrm{Cu}_{1}$ adatoms (Figure 5, Table 1, and Figure 7). In particular, DFT predicted $\mathrm{CO}$ on $\mathrm{Cu}_{5}$ clusters giving three different peaks at 2046, 2030, and $1973 \mathrm{~cm}^{-1}$ accounting for one, three, and one $\mathrm{CO}$ molecule, respectively. Since the signal at $2030 \mathrm{~cm}^{-1}\left(\Delta \tilde{\nu}_{\mathrm{DFT}}=19\right)$ corresponds to three vibrations $\left(2032,2030,2029 \mathrm{~cm}^{-1}\right)$, we expect this band to be the most evident in the IR spectrum, matching exactly with the experimental band $\left(\Delta \tilde{\nu}_{\exp }=19\right)$. The formation energy of such $\mathrm{Cu}_{5}$ clusters is calculated to change from highly endothermic, $G_{\text {form }}=110 \mathrm{~kJ} \mathrm{~mol}^{-1}$, at low CO pressure, to highly exothermic, $G_{\text {form }}=-118 \mathrm{~kJ} \mathrm{~mol}^{-1}$, at high $\mathrm{CO}$ pressure, when they accommodate 5 adsorbed $\mathrm{CO}$ molecules (Table 1). This assignment agrees with the HP-STM characterization of such clusters on $\mathrm{Cu}(100)$ ( 0.25 mbar CO pressure) by Salmeron and co-workers. ${ }^{39}$ When exposing a $\mathrm{Cu}(110)$ surface to 0.03 mbar $\mathrm{CO}$ at room temperature, ${ }^{38}$ an absorption band at $2099 \mathrm{~cm}^{-1}$ was observed, assigned to $\mathrm{CO}$ adsorbed on $\mathrm{Cu}$ "end" atoms $(\mathrm{CN}=6)$ of short linear $\mathrm{Cu}$ clusters. Although a straightforward comparison is difficult for different single crystal surfaces, the CO peaks at 2093, 2099, and $2103 \mathrm{~cm}^{-1}$ are all in the "ballpark" of low-coordinated $\mathrm{Cu}$ sites.
The formation of clusters from $\mathrm{Cu}_{1}$ was followed by a timedependent PM-IRAS experiment in $0.1 \mathrm{mbar} \mathrm{CO}$ at $300 \mathrm{~K}$ (Figure 6b). The peak at $2093 \mathrm{~cm}^{-1}$ assigned to $\mathrm{Cu}$ clusters increased, whereas the $2103 \mathrm{~cm}^{-1}$ peak assigned to $\mathrm{CO} / \mathrm{Cu}_{1}$ decreased in intensity. This indicates that $\mathrm{Cu}$ clusters are formed by coalescence of $\mathrm{Cu}_{1}$.

The $\mathrm{Cu}(100)$ surface reconstruction was further confirmed by two PM-IRAS experiments at 1 and 5 mbar CO pressure, see Figure 8. At 1 mbar (Figure 8a), a main band was observed at $2095 \mathrm{~cm}^{-1}$ and was assigned to $\mathrm{CO}$ adsorbed on $\mathrm{Cu}$ clusters. The shoulder at $2102 \mathrm{~cm}^{-1}$ was again attributed to $\mathrm{CO} / \mathrm{Cu}_{1}$ complexes. At this pressure, the $\mathrm{Cu}_{1}$ species disappeared faster and $\mathrm{Cu}$ clusters formed in a shorter time. A dynamical equilibrium between detachment of $\mathrm{Cu}_{1}$ adatoms from steps and $\mathrm{Cu}$ cluster formation explains why no strong timedependent changes were observed. At 5 mbar (Figure 8b), only the band of $\mathrm{CO}$ adsorbed on $\mathrm{Cu}$ clusters was detected due to the faster coalescence of $\mathrm{Cu}_{1}$ adatoms. Finally, at this elevated pressure, an equilibrium state was reached, and the detachment of $\mathrm{Cu}_{1}$ atoms from step edges and their coalescence to $\mathrm{Cu}$ clusters led to the formation of a rough $\mathrm{Cu}$ surface.

After exposure to $1 \mathrm{mbar} \mathrm{CO}$ at room temperature, the highpressure spectroscopic cell was evacuated; the sample was transferred in UHV to the upper UHV chamber, and a thorough postreaction analysis was carried out by LEED, XPS, and TPD. Using LEED (Figure 1c), an ordered pattern could not be observed anymore, and the background was brighter than in a previous analysis (the LEED and camera settings were the same as those of Figure $1 \mathrm{a}, \mathrm{b}$ ), suggesting surface reconstruction (roughening).

Using XPS at $300 \mathrm{~K}$ and $3 \times 10^{-10} \mathrm{mbar}$ (Figure $2 \mathrm{~d}$ ), an oxygen species at $530.2 \mathrm{eV}$ (coverage of $0.38 \mathrm{ML}$ ) and a 
Table 2. Summary of Binding and Vibrational Energies of the Detected Species ${ }^{a}$

\begin{tabular}{llc}
\multicolumn{1}{c}{ species } & XPS O 1s BE $/ \mathrm{eV}$ & XPS C $1 \mathrm{~s} \mathrm{BE} / \mathrm{eV}$ \\
$\mathrm{Cu}(100)-c(2 \times 2) \mathrm{CO}$ & $538.3,534.5,533.2$ & $293.2,288.9,286.2$ \\
$\mathrm{CO} / \mathrm{Cu}$ defect sites \\
carbon \\
oxygen
\end{tabular}

carbon species at $284.5 \mathrm{eV}(0.27 \mathrm{ML})$ were detected. Note that no $\mathrm{O} 1 \mathrm{~s}$ and a much smaller $\mathrm{C} 1 \mathrm{~s}$ signals were detected after exposing the sample at $300 \mathrm{~K}$ for $40 \mathrm{~min}$ to $1 \mathrm{mbar} \mathrm{Ar}$ instead of $\mathrm{CO}$ (Figure 2c).

On the basis of refs 37 and 71, the $530.2 \mathrm{eV}$ species was assigned to adsorbed $\mathrm{O}$. Adsorbed molecular $\mathrm{CO}$ can be excluded as origin because of the different binding energy and absence of satellite peaks (cf., Figure 2a; the same holds for C 1s discussed below). Note also that the XPS spectrum was acquired in UHV and that TPD had indicated that even on a roughened $\mathrm{Cu}$ surface $\mathrm{CO}$ desorbed around $200 \mathrm{~K}$ (Figure $3 \mathrm{~b})$. Water contamination can also be excluded since XPS was acquired in UHV at $300 \mathrm{~K}$ and the water $\mathrm{O}$ 1s peak would be around $531.5-532.5 \mathrm{eV},{ }^{72}$ very different from the observed $530.2 \mathrm{eV}$ (adsorbed O) species.

The C 1s peak at $284.5 \mathrm{eV}$ clearly does not originate from adsorbed CO but could, in principle, be due to adventitious carbon. However, as discussed above, the gold-coated walls and clean gases strongly limit that (cf., Figures $2 b, c$ and $3 b, c$ ). Furthermore, exposing, e.g., $\operatorname{Pd}(111)$, which does not dissociate $\mathrm{CO}$, to $1 \mathrm{mbar} \mathrm{CO}$ for longer times did not produce such a pronounced carbon peak (see, e.g., ref 73).

The straightforward interpretation of the presence of oxygen and carbon is that $\mathrm{CO}$ dissociation, $\mathrm{CO}^{*} \rightarrow \mathrm{C}^{*}+\mathrm{O}^{*}($ ref 74$)$, had occurred, which is not favorable on the pristine single crystalline surface ( $\mathrm{CO}$ adsorption on $\mathrm{Cu}(100)$ in UHV is reversible). This would demonstrate the effect of high-pressure $\mathrm{CO}$ and surface roughening on the intrinsic catalytic properties of $\mathrm{Cu}$. It is in line with studies of $\mathrm{Cu}$ nanoclusters on alumina ${ }^{75}$ and of the stepped $\mathrm{Cu}(211)$ surface, ${ }^{76}$ indicating that both were active toward $\mathrm{CO}$ dissociation.

To further examine the identity of the $\mathrm{O} 1 \mathrm{~s}$ and $\mathrm{C} 1 \mathrm{~s}$ species on the CO-induced roughened surface (after exposure to 1 mbar $\mathrm{CO}$ at $300 \mathrm{~K}$ for $40 \mathrm{~min}$ ), the surface was cooled from 300 to $120 \mathrm{~K}$ in $1 \times 10^{-7}$ mbar CO $(\sim 40 \mathrm{~L} \mathrm{CO})$ and characterized by TPD. As shown in Figure $3 \mathrm{~d}$, hardly any CO had adsorbed and only a tiny amount of $\mathrm{CO}_{2}$ desorbed ( $\mathrm{CO}$ at $450 \mathrm{~K}$ is a fragment of $\mathrm{CO}_{2}$ ). Although spectra were enlarged by a factor of 10 , the amount of $\mathrm{CO}$ desorbing from the roughened $\mathrm{Cu}$ surface was negligible $(\sim 5 \%)$ when compared to that desorbing from the as-prepared clean sample (Figure $3 a)$. The surface remained $\mathrm{O} / \mathrm{C}$ covered, as indicated by a follow-up TPD (Figure S3) showing very little $\mathrm{CO}$ adsorption and no $\mathrm{CO}_{2}$ desorption.

Even $\mathrm{Cu}$ sites free from $\mathrm{O}$ and $\mathrm{C}(\sim 0.35 \mathrm{ML})$ seemed not energetically favorable for $\mathrm{CO}$ adsorption because of neighboring $\mathrm{O}$ and $\mathrm{C}$ adatoms. In a following experiment, the $\mathrm{Cu}$ surface (still) covered by adsorbed $\mathrm{O}$ and adsorbed $\mathrm{C}$ was exposed to $8 \times 10^{-7} \mathrm{mbar} \mathrm{CO}$ at $510 \mathrm{~K}$ for $10 \mathrm{~min}$. The $\mathrm{CO}$ reacted with most of the adsorbed $\mathrm{O}$, whereas the $\mathrm{C} 1 \mathrm{~s}$ signal remained nearly the same (Figure 2e). After this treatment, part of the surface was free from adsorbed $\mathrm{O}$ and therefore able to adsorb $\mathrm{CO}$ again, as indicated by CO-TPD (Figure 3e).
Altogether, the control experiments suggested that $\mathrm{CO}$ dissociation had occurred. All detected species are summarized in Table 2. No changes in the oxidation state of (metallic) copper were observed throughout the experiments (Figure S4).

Nevertheless, although we have used purified gases and carried out all high-pressure exposures in the gold-coated cell, mbar pressure experiments may still encounter problems with contaminations. One could argue that the blind test with $\mathrm{Ar}$ may not be conclusive, as mbars of $\mathrm{CO}$ may replace contaminations from the chamber walls more effectively than Ar does. However, as mentioned, exposing $\operatorname{Pd}(111)$, which does not dissociate $\mathrm{CO}$, to $1 \mathrm{mbar} \mathrm{CO}$ for longer times did not produce such a pronounced carbon peak or any $\mathrm{O} 1 \mathrm{~s}$ species, ${ }^{73}$ supporting the current picture of $\mathrm{CO}$ dissociation on roughened $\mathrm{Cu}$.

\section{SUMMARY AND CONCLUSIONS}

The room temperature adsorption of $\mathrm{CO}$ under mbar gas pressure caused reconstruction of the $\mathrm{Cu}(100)$ surface, which was characterized in situ and ex situ by LEED, XPS, TPD, PMIRAS, and DFT.

Compared to the $c(2 \times 2) \mathrm{CO}$ overlayer on smooth $\mathrm{Cu}(100)$ terraces, $\mathrm{CO}$ on step sites was found to adsorb more strongly by $\Delta E=53-44=9 \mathrm{~kJ} \mathrm{~mol}^{-1}$ and was characterized by a vibrational band at a higher wavenumber $\Delta \tilde{\nu}_{\exp }=2092-2082$ $\mathrm{cm}^{-1}=10 \mathrm{~cm}^{-1}$ (at $1 \times 10^{-7}$ mbar pressure). These findings are in line with DFT simulations, which yielded $\Delta E=11 \mathrm{~kJ}$ $\mathrm{mol}^{-1}$ and $\Delta \tilde{\nu}_{\mathrm{DFT}}=8 \mathrm{~cm}^{-1}$ for these adsorption sites.

At $0.1 \mathrm{mbar} \mathrm{CO}$ pressure and $200-300 \mathrm{~K}, \mathrm{Cu}_{1}$ adatoms on $\mathrm{Cu}(100)$ were detected through characteristic vibrational bands. The formation of $\mathrm{Cu}_{1}$ was calculated to be only slightly endothermic when $\mathrm{CO}$ is adsorbed, $G_{\text {form }}=4 \mathrm{~kJ} \mathrm{~mol}^{-1}$. Thus, the formation of $\mathrm{CO} / \mathrm{Cu}_{1}$ complexes is affected by the $\mathrm{CO}$ pressure and temperature, as observed experimentally. The vibrational band of $\mathrm{CO}$ adsorbed on $\mathrm{Cu}_{1}$ adatoms was found to be $\Delta \tilde{\nu}_{\text {exp }}=2112-2082 \mathrm{~cm}^{-1}=30 \mathrm{~cm}^{-1}$ higher than on $\mathrm{Cu}(100)$ terraces, which is in line with the respective calculated value of $\Delta \tilde{\nu}_{\mathrm{DFT}}=35 \mathrm{~cm}^{-1}$.

At $300 \mathrm{~K}, \mathrm{Cu}_{1}$ adatoms and $\mathrm{Cu}$ clusters coexisted in dynamic equilibrium, which was shifted toward clusters at 1 and 5 mbar $\mathrm{CO}$ pressure. DFT simulations of $\mathrm{Cu}_{5}$ clusters on $\mathrm{Cu}(100)$ showed that these clusters can accommodate $5 \mathrm{CO}$ molecules and that their formation is highly exothermic, $G_{\text {form }}=-118 \mathrm{~kJ}$ $\mathrm{mol}^{-1}$ under high $\mathrm{CO}$ pressure. $\mathrm{CO}$ adsorbed on $\mathrm{Cu}_{5}$ clusters was calculated to preferentially vibrate at $\Delta \tilde{\nu}_{\mathrm{DFT}}=19 \mathrm{~cm}^{-1}$, which favorably agrees with the experimentally observed band at $2093 \mathrm{~cm}^{-1}\left(\Delta \tilde{\nu}_{\exp }=19 \mathrm{~cm}^{-1}\right)$.

XPS and TPD analysis suggested the $\mathrm{Cu}(100)$ surface roughened by mbar $\mathrm{CO}$ exposure to be active for $\mathrm{CO}$ dissociation. After exposing $\mathrm{Cu}(100)$ to $1 \mathrm{mbar} \mathrm{CO}$ at room temperature, XPS revealed the presence of carbon, at BE 284.5 $\mathrm{eV}$, and adsorbed oxygen, at $\mathrm{BE} 530.2 \mathrm{eV}$. The adsorbed oxygen could react with $\mathrm{CO}$ gas at $510 \mathrm{~K}$, leaving $\mathrm{C}$ unaffected. Since all high-pressure exposures were performed with purified 
gases and in a gold-coated cell, contamination effects should be very limited.

The observed reconstruction of $\mathrm{Cu}$ surfaces induced by mbar $\mathrm{CO}$ exposure may have important implications on processes relying on copper-based catalysts and CO-containing reaction mixtures, e.g., by promoting the formation of lowcoordinated active copper sites and/or increasing the surface density of the latter.

\section{ASSOCIATED CONTENT}

\section{S Supporting Information}

The Supporting Information is available free of charge on the ACS Publications website at DOI: 10.1021/acs.jpcc.8b07668.

XPS and TPD data of clean $\mathrm{Cu}(100)$ and after various (high-pressure) $\mathrm{CO}$ or Ar exposures, and DFT-derived energetics and vibrational frequencies of $\mathrm{CO}$ on $\mathrm{Cu}_{5}$ / $\mathrm{Cu}(100)(\mathrm{PDF})$

\section{AUTHOR INFORMATION}

\section{Corresponding Author}

*E-mail: guenther.rupprechter@tuwien.ac.at.

\section{ORCID}

Laura Falivene: 0000-0003-1509-6191

Luigi Cavallo: 0000-0002-1398-338X

Günther Rupprechter: 0000-0002-8040-1677

\section{Notes}

The authors declare no competing financial interest.

\section{ACKNOWLEDGMENTS}

This work was supported by the Austrian Science Fund (FWF) through projects DK+ Solids4Fun (W1243) and ComCat (I1041-N28), and by King Abdullah University of Science and Technology (KAUST). This research used resources of the Supercomputing Laboratory at KAUST.

\section{REFERENCES}

(1) Weissermel, K.; Arpe, H.-J. Industrial Organic Chemistry, 3rd ed.; Wiley-VCH: Weinheim, 1997.

(2) Nerlov, J.; Sckerl, S.; Wambach, J.; Chorkendorff, I. Methanol Synthesis from $\mathrm{CO}_{2}, \mathrm{CO}$ and $\mathrm{H}_{2}$ over $\mathrm{Cu}(100)$ and $\mathrm{Cu}(100)$ Modified by Ni and Co. Appl. Catal., A 2000, 191, 97-109.

(3) Behrens, M.; Studt, F.; Kasatkin, I.; Kuhl, S.; Hävecker, M.; Abild-Pedersen, F.; Zander, S.; Girgsdies, F.; Kurr, P.; Kniep, B. L.; et al. The Active Site of Methanol Synthesis over $\mathrm{Cu} / \mathrm{ZnO} / \mathrm{Al}_{2} \mathrm{O}_{3}$ Industrial Catalysts. Science 2012, 336, 893-897.

(4) Graciani, J.; Mudiyanselage, K.; Xu, F.; Baber, A. E.; Evans, J.; Senanayake, S. D.; Stacchiola, D. J.; Liu, P.; Hrbek, J.; Sanz, J. F.; et al. Highly Active Copper-Ceria and Copper-Ceria-Titania Catalysts for Methanol Synthesis from $\mathrm{CO}_{2}$. Science 2014, 345, 546-550.

(5) Grabow, L. C.; Mavrikakis, M. Mechanism of Methanol Synthesis on $\mathrm{Cu}$ through $\mathrm{CO}_{2}$ and $\mathrm{CO}$ Hydrogenation. ACS Catal. 2011, 1, 365-384.

(6) Kattel, S.; Ramirez, P. J.; Chen, J. G.; Rodriguez, J. A.; Liu, P. Active Sites for $\mathrm{CO}_{2}$ Hydrogenation to Methanol on $\mathrm{Cu} / \mathrm{ZnO}$ Catalysts. Science 2017, 355, 1296-1299.

(7) Nakamura, J.; Fujitani, T.; Kuld, S.; Helveg, S.; Chorkendorff, I.; Sehested, J. Comment on "Active Sites for $\mathrm{CO}_{2}$ Hydrogenation to Methanol on $\mathrm{Cu} / \mathrm{ZnO}$ Catalysts. Science 2017, 357, 2.

(8) Li, C. W.; Ciston, J.; Kanan, M. W. Electroreduction of Carbon Monoxide to Liquid Fuel on Oxide-Derived Nanocrystalline Copper. Nature 2014, 508, 504-507.

(9) Xiao, H.; Cheng, T.; Goddard, W. A.; Sundararaman, R. Mechanistic Explanation of the $\mathrm{pH}$ Dependence and Onset Potentials for Hydrocarbon Products from Electrochemical Reduction of $\mathrm{CO}$ on $\mathrm{Cu}$ (111). J. Am. Chem. Soc. 2016, 138, 483-486.

(10) Xiao, H.; Cheng, T.; Goddard, W. A. Atomistic Mechanisms Underlying Selectivities in $\mathrm{C}-1$ and $\mathrm{C}-2$ Products from Electrochemical Reduction of $\mathrm{CO}$ on $\mathrm{Cu}(111)$. J. Am. Chem. Soc. 2017, 139, 130-136.

(11) Opitz, A. K.; Nenning, A.; Rameshan, C.; Kubicek, M.; Götsch, T.; Blume, R.; Hävecker, M.; Knop-Gericke, A.; Rupprechter, G.; Klötzer, B.; et al. Surface Chemistry of Perovskite-Type Electrodes During High Temperature $\mathrm{CO}_{2}$ Electrolysis Investigated by Operando Photoelectron Spectroscopy. ACS Appl. Mater. Interfaces 2017, 9, 35847-35860.

(12) Sauer, J.; Freund, H.-J. Models in Catalysis. Catal. Lett. 2015, $145,109-125$.

(13) Freund, H.-J. The Surface Science of Catalysis and More, Using Ultrathin Oxide Films as Templates: A Perspective. J. Am. Chem. Soc. 2016, 138, 8985-8996.

(14) Freund, H.-J.; Bäumer, M.; Kuhlenbeck, H. Catalysis and Surface Science: What do we Learn from Studies of Oxide-Supported Cluster Model Systems? Adv. Catal. 2000, 45, 333-384.

(15) Freund, H.-J.; Bäumer, M.; Libuda, J.; Risse, T.; Rupprechter, G.; Shaikhutdinov, S. Preparation and Characterization of Model Catalysts: from Ultrahigh Vacuum to In Situ Conditions at the Atomic Dimension. J. Catal. 2003, 216, 223-235.

(16) Chesters, M. A.; Pritchard, J.; Sims, M. L. Infrared Spectrum and Surface Potential of Carbon Monoxide Chemisorbed on a Copper (100) Single-Crystal Surface. J. Chem. Soc. D 1970, 0, 14541455.

(17) Horn, K.; Pritchard, J. Infrared Spectrum of CO Chemisorbed on $\mathrm{Cu}(100)$. Surf. Sci. 1976, 55, 701-704.

(18) Persson, B. N. J.; Ryberg, R. Vibrational Interaction Between Molecules Adsorbed on a Metal Surface - The Dipole-Dipole Interaction. Phys. Rev. B: Condens. Matter Mater. Phys. 1981, 24, 6954-6970.

(19) Ryberg, R. Carbon Monoxide Adsorbed on $\mathrm{Cu}(100)$ Studied by Infrared Spectroscopy. Surf. Sci. 1982, 114, 627-641.

(20) Fuggle, J. C.; Umbach, E.; Menzel, D.; Wandelt, K.; Brundle, C. R. Adsorbate Line-Shapes and Multiple Lines in XPS - Comparison of Theory and Experiment. Solid State Commun. 1978, 27, 65-69.

(21) Norton, P. R.; Tapping, R. L.; Goodale, J. W. High-Resolution Photoemission Study of Physisorption and Chemisorption of $\mathrm{CO}$ on Copper and Gold. Surf. Sci. 1978, 72, 33-44.

(22) Wurth, W.; Coulman, D.; Puschmann, A.; Menzel, D.; Umbach, E. Relation Between X-Ray Photoemission Binding Energies and Absorption Resonance Energies for CO Adsorbates. Phys. Rev. B: Condens. Matter Mater. Phys. 1990, 41, 12933-12936.

(23) Antonsson, H.; Nilsson, A.; Martensson, N.; Panas, I.; Siegbahn, P. E. M. Vibrational Motion and Geometrical Structure in Adsorbed CO Studied by Core Level Photoelectron Spectroscopy. J. Electron Spectrosc. Relat. Phenom. 1990, 54, 601-613.

(24) Pritchard, J. Structure of $\mathrm{CO}$ Adlayers on $\mathrm{Cu}(100)$ and $\mathrm{Cu}(111)$. Surf. Sci. 1979, 79, 231-244.

(25) Andersson, S.; Pendry, J. B. Structure of CO Adsorbed on $\mathrm{Cu}(100)$ and $\mathrm{Ni}(100)$. Phys. Rev. Lett. 1979, 43, 363-366.

(26) Uvdal, P.; Karlsson, P. A.; Nyberg, C.; Andersson, S.; Richardson, N. V. On the Structure of Dense CO Overlayers. Surf. Sci. 1988, 202, 167-182.

(27) Harris, A. L.; Levinos, N. J.; Rothberg, L.; Dubois, L. H.; Dhar, L.; Shane, S. F.; Morin, M. Vibrational-Energy Transfer to Metal Surfaces Probed by Sum Generation - $\mathrm{CO} / \mathrm{Cu}(100)$ and $\mathrm{CH}_{3} \mathrm{~S} /$ $\mathrm{Ag}(111)$. J. Electron Spectrosc. Relat. Phenom. 1990, 54, 5-16.

(28) Morin, M.; Levinos, N. J.; Harris, A. L. Vibrational-Energy Transfer of $\mathrm{CO} / \mathrm{Cu}(100)$ - Nonadiabatic Vibration Electron Coupling. J. Chem. Phys. 1992, 96, 3950-3956.

(29) Germer, T. A.; Stephenson, J. C.; Heilweil, E. J.; Cavanagh, R. R. Picosecond Time-Resolved Adsorbate Response to Substrate Heating - Spectroscopy and Dynamics of $\mathrm{CO} / \mathrm{Cu}(100)$. J. Chem. Phys. 1994, 101, 1704-1716. 
(30) Taylor, A. O.; Pritchard, J. CO Adsorbed on $\mathrm{Cu}(100)$ - RAIRS at Ultrahigh Vacuum and Higher Pressures. J. Chem. Soc., Faraday Trans. 1990, 86, 2743-2748.

(31) Truong, C. M.; Rodriguez, J. A.; Goodman, D. W. CO Adsorption-Isotherms on $\mathrm{Cu}(100)$ at Elevated Pressures and Temperatures Using Infrared Reflection Absorption-Spectroscopy. Surf. Sci. 1992, 271, L385-L391.

(32) Somorjai, G. A. Modern Surface Science and Surface Technologies: An Introduction. Chem. Rev. 1996, 96, 1223-1235.

(33) Tao, F.; Dag, S.; Wang, L. W.; Liu, Z.; Butcher, D. R.; Bluhm, H.; Salmeron, M.; Somorjai, G. A. Break-Up of Stepped Platinum Catalyst Surfaces by High CO Coverage. Science 2010, 327, 850-853.

(34) Rupprechter, G.; Freund, H.-J. Adsorbate-induced Restructuring and Pressure-Dependent Adsorption on Metal Nanoparticles Studied by Electron Microscopy and Sum Frequency Generation Spectroscopy. Top. Catal. 2000, 14, 3-14.

(35) Haghofer, A.; Sonström, P.; Fenske, D.; Föttinger, K.; Schwarz, S.; Bernardi, J.; Al-Shamery, K.; Bäumer, M.; Rupprechter, G. Colloidally Prepared Pt Nanowires versus Impregnated Pt Nanoparticles: Comparison of Adsorption and Reaction Properties. Langmuir 2010, 26, 16330-16338.

(36) Podda, N.; Corva, M.; Mohamed, F.; Feng, Z.; Dri, C.; Dvorak, F.; Matolin, V.; Comelli, G.; Peressi, M.; Vesselli, E. Experimental and Theoretical Investigation of the Restructuring Process Induced by $\mathrm{CO}$ at Near Ambient Pressure: Pt Nanoclusters on Graphene/Ir(111). ACS Nano 2017, 11, 1041-1053.

(37) Eren, B.; Zherebetskyy, D.; Patera, L. L.; Wu, C. H.; Bluhm, H.; Africh, C.; Wang, L. W.; Somorjai, G. A.; Salmeron, M. Activation of $\mathrm{Cu}(111)$ Surface by Decomposition into Nanoclusters Driven by CO Adsorption. Science 2016, 351, 475-478.

(38) Eren, B.; Liu, Z. Y.; Stacchiola, D.; Somorjai, G. A.; Salmeron, M. Structural Changes of $\mathrm{Cu}(110)$ and $\mathrm{Cu}(110)-(2 \times 1)$-O Surfaces under Carbon Monoxide in the Torr Pressure Range Studied with Scanning Tunneling Microscopy and Infrared Reflection Absorption Spectroscopy. J. Phys. Chem. C 2016, 120, 8227-8231.

(39) Eren, B.; Zherebetskyy, D.; Hao, Y. B.; Patera, L. L.; Wang, L. W.; Somorjai, G. A.; Salmeron, M. One-dimensional Nanoclustering of the $\mathrm{Cu}(100)$ Surface under CO Gas in the mbar Pressure Range. Surf. Sci. 2016, 651, 210-214.

(40) Rupprechter, G.; Dellwig, T.; Unterhalt, H.; Freund, H.-J. CO Adsorption on $\mathrm{Ni}(100)$ and $\mathrm{Pt}(111)$ Studied by Infrared-Visible Sum Frequency Generation Spectroscopy: Design and Application of an SFG-Compatible UHV-High-Pressure Reaction Cell. Top. Catal. 2001, 15, 19-26.

(41) Rupprechter, G. Surface Vibrational Spectroscopy from Ultrahigh Vacuum to Atmospheric Pressure: Adsorption and Reactions on Single Crystals and Nanoparticle Model Catalysts Monitored by Sum Frequency Generation Spectroscopy. Phys. Chem. Chem. Phys. 2001, 3, 4621-4632.

(42) Rodriguez de la Fuente, O.; Borasio, M.; Galletto, P.; Rupprechter, G.; Freund, H.-J. The Influence of Surface Defects on Methanol Decomposition on $\operatorname{Pd}(111)$ Studied by XPS and PM-IRAS. Surf. Sci. 2004, 566, 740-745.

(43) Kaichev, V. V.; Morkel, M.; Unterhalt, H.; Prosvirin, I. P.; Bukhtiyarov, V. I.; Rupprechter, G.; Freund, H.-J. C-O bond Scission on "Defect-rich and Perfect" $\operatorname{Pd}(111)$ ? Surf. Sci. 2004, 566, 10241029.

(44) Rupprechter, G.; Kaichev, V. V.; Unterhalt, H.; Morkel, A.; Bukhtiyarov, V. I. CO Dissociation and CO Hydrogenation on Smooth and Ion-Bombarded Pd(111): SFG and XPS Spectroscopy at mbar Pressures. Appl. Surf. Sci. 2004, 235, 26-31.

(45) Borasio, M.; Rodriguez de la Fuente, O.; Rupprechter, G.; Freund, H.-J. In Situ Studies of Methanol Decomposition and Oxidation on Pd(111) by PM-IRAS and XPS Spectroscopy. J. Phys. Chem. B 2005, 109, 17791-17794.

(46) Rameshan, C.; Weilach, C.; Stadlmayr, W.; Penner, S.; Lorenz, H.; Hävecker, M.; Blume, R.; Rocha, T.; Teschner, D.; Knop-Gericke, A.; et al. Steam Reforming of Methanol on PdZn Near-Surface Alloys on Pd(111) and Pd Foil Studied by In-Situ XPS, LEIS and PM-IRAS. J. Catal. 2010, 276, 101-113.

(47) Rameshan, C.; Stadlmayr, W.; Weilach, C.; Penner, S.; Lorenz, H.; Hävecker, M.; Blume, R.; Rocha, T.; Teschner, D.; Knop-Gericke, A.; et al. Subsurface-Controlled $\mathrm{CO}_{2}$ Selectivity of PdZn Near-Surface Alloys in $\mathrm{H}_{2}$ Generation by Methanol Steam Reforming. Angew. Chem., Int. Ed. 2010, 49, 3224-3227.

(48) Stadlmayr, W.; Rameshan, C.; Weilach, C.; Lorenz, H.; Hävecker, M.; Blume, R.; Rocha, T.; Teschner, D.; Knop-Gericke, A.; Zemlyanov, D.; et al. Temperature-Induced Modifications of PdZn Layers on $\operatorname{Pd}(111)$. J. Phys. Chem. C 2010, 114, 10850-10856.

(49) Weilach, C.; Kozlov, S. M.; Holzapfel, H. H.; Föttinger, K.; Neyman, K. M.; Rupprechter, G. Geometric Arrangement of Components in Bimetallic PdZn/Pd(111) Surfaces Modified by CO Adsorption: A Combined Study by Density Functional Calculations, Polarization-Modulated Infrared Reflection Absorption Spectroscopy, and Temperature-Programmed Desorption. J. Phys. Chem. C 2012, 116, 18768-18778.

(50) Holzapfel, H. H.; Wolfbeisser, A.; Rameshan, C.; Weilach, C.; Rupprechter, G. PdZn Surface Alloys as Models of Methanol Steam Reforming Catalysts: Molecular Studies by LEED, XPS, TPD and PM-IRAS. Top. Catal. 2014, 57, 1218-1228.

(51) Anic, K.; Bukhtiyarov, A. V.; Li, H.; Rameshan, C.; Rupprechter, G. CO Adsorption on Reconstructed $\operatorname{Ir}(100)$ Surfaces from UHV to mbar Pressure: A LEED, TPD, and PM-IRAS Study. J. Phys. Chem. C 2016, 120, 10838-10848.

(52) Reichl, W.; Rosina, G.; Rupprechter, G.; Zimmermann, C.; Hayek, K. Ultrahigh Vacuum Compatible All-Glass High Pressure Reaction Cell for Accurate and Reproducible Measurement of Small Reaction Rates. Rev. Sci. Instrum. 2000, 71, 1495-1499.

(53) Kung, K. Y.; Chen, P.; Wei, F.; Rupprechter, G.; Shen, Y. R.; Somorjai, G. A. Ultrahigh Vacuum High-Pressure Reaction System for 2-Infrared 1-Visible Sum Frequency Generation Studies. Rev. Sci. Instrum. 2001, 72, 1806-1809.

(54) Roiaz, M.; Pramhaas, V.; Li, X.; Rameshan, C.; Rupprechter, G. Atmospheric Pressure Reaction Cell for Operando Sum Frequency Generation Spectroscopy of Ultrahigh Vacuum Grown Model Catalysts. Rev. Sci. Instrum. 2018, 89 (4), 10.

(55) Rupprechter, G. Surface Vibrational Spectroscopy on Noble Metal Catalysts from Ultrahigh Vacuum to Atmospheric Pressure. Annu. Rep. Prog. Chem., Sect. C: Phys. Chem. 2004, 100, 237-311.

(56) Rupprechter, G. Sum Frequency Generation and PolarizationModulation Infrared Reflection Absorption Spectroscopy of Functioning Model Catalysts from Ultrahigh Vacuum to Ambient Pressure. In Advances in Catalysis; Gates, B. C., Knözinger, H., Eds.; Elsevier Academic Press Inc: San Diego, 2007; Vol. 51, pp 133-263.

(57) Rupprechter, G.; Weilach, C. Spectroscopic Studies of SurfaceGas Interactions and Catalyst Restructuring at Ambient Pressure: Mind the Gap! J. Phys.: Condens. Matter 2008, 20, 184019.

(58) Föttinger, K.; Weilach, C.; Rupprechter, G. Sum Frequency Generation and Infrared Reflection Absorption Spectroscopy. In Characterization of Solid Materials and Heterogeneous Catalysis: From Structure to Surface Reactivity; Che, M., Védrine, J., Eds.; Wiley-VCH: Weinheim, 2012; pp 211-252.

(59) Tillborg, H.; Nilsson, A.; Martensson, N. Shake-Up and ShakeOff Structures in Core-Level Photoemission Spectra from Adsorbates. J. Electron Spectrosc. Relat. Phenom. 1993, 62, 73-93.

(60) Li, H.; Choi, J. I. J.; Mayr-Schmölzer, W.; Weilach, C.; Rameshan, C.; Mittendorfer, F.; Redinger, J.; Schmid, M.; Rupprechter, G. Growth of an Ultrathin Zirconia Film on $\mathrm{Pt}_{3} \mathrm{Zr}$ Examined by High-Resolution X-ray Photoelectron Spectroscopy, Temperature-Programmed Desorption, Scanning Tunneling Microscopy, and Density Functional Theory. J. Phys. Chem. C 2015, 119, 2462-2470.

(61) Redhead, P. A. Thermal Desorption of Gases. Vacuum 1962, 12, 203-244.

(62) Vollmer, S.; Witte, G.; Wöll, C. Determination of Site Specific Adsorption Energies of CO on Copper. Catal. Lett. 2001, 77, 97-101. 
(63) Woodruff, D. P.; Hayden, B. E.; Prince, K.; Bradshaw, A. M. Dipole Coupling and Chemical Shifts in IRAS of CO Adsorbed on $\mathrm{Cu}(110)$. Surf. Sci. 1982, 123, 397-412.

(64) Bradshaw, A. M.; Pritchard, J.; Sims, M. L. Reflection Spectroscopy of Chemisorbed Carbon Monoxide Under Ultrahigh Vacuum Conditions. Chem. Commun. 1968, 23, 1519-1520.

(65) Tompkins, H. G.; Greenler, R. G. Experimental Development of Reflection-Absorption Spectroscopy - Infrared Spectrum of Carbon Monoxide Adsorbed on Copper and Copper Oxide. Surf. Sci. 1971, 28, 194-208.

(66) Pritchard, J.; Catterick, T.; Gupta, R. K. Infrared Spectroscopy of Chemisorbed Carbon Monoxide on Copper. Surf. Sci. 1975, 53, 120.

(67) Stobie, R. W.; Rao, B.; Dignam, M. J. Infrared Ellipsometry of Adsorbed Molecules - CO on Evaporated Cu Films. Surf. Sci. 1976, 56, 334-353.

(68) Seki, H.; Takada, M.; Tanabe, T.; Wadayama, T.; Hatta, A. Infrared Absorption Study of CO Chemisorption on Copper Island Films. Surf. Sci. 2002, 506, 23-32.

(69) Roiaz, M.; Monachino, E.; Dri, C.; Greiner, M.; Knop-Gericke, A.; Schlögl, R.; Comelli, G.; Vesselli, E. Reverse Water-Gas Shift or Sabatier Methanation on $\mathrm{Ni}(110)$ ? Stable Surface Species at NearAmbient Pressure. J. Am. Chem. Soc. 2016, 138, 4146-4154.

(70) Yang, F.; Chen, M. S.; Goodman, D. W. Sintering of Au Particles Supported on $\mathrm{TiO}_{2}(110)$ during CO Oxidation. J. Phys. Chem. C 2009, 113, 254-260.

(71) Eren, B.; Lichtenstein, L.; Wu, C. H.; Bluhm, H.; Somorjai, G. A.; Salmeron, M. Reaction of CO with Preadsorbed Oxygen on LowIndex Copper Surfaces: An Ambient Pressure X-ray Photoelectron Spectroscopy and Scanning Tunneling Microscopy Study. J. Phys. Chem. C 2015, 119, 14669-14674.

(72) Yamamoto, S.; Bluhm, H.; Andersson, K.; Ketteler, G.; Ogasawara, H.; Salmeron, M.; Nilsson, A. In Situ X-ray Photoelectron Spectroscopy Studies of Water on Metals and Oxides at Ambient Conditions. J. Phys.: Condens. Matter 2008, 20, 184025.

(73) Kaichev, V. V.; Prosvirin, I. P.; Bukhtiyarov, V. I.; Unterhalt, H.; Rupprechter, G.; Freund, H.-J. High-Pressure Studies of CO Adsorption on $\mathrm{Pd}(111)$ by X-ray Photoelectron Spectroscopy and Sum-Frequency Generation. J. Phys. Chem. B 2003, 107, 3522-3527.

(74) Holleman, A. F.; Wiberg, E. Inorganic Chemistry, 1st ed.; Academic Press: San Diego, 2001.

(75) Olmos-Asar, J. A.; Monachino, E.; Dri, C.; Peronio, A.; Africh, C.; Lacovig, P.; Comelli, G.; Baldereschi, A.; Peressi, M.; Vesselli, E. $\mathrm{CO}$ on Supported $\mathrm{Cu}$ Nanoclusters: Coverage and Finite Size Contributions to the Formation of Carbide via the Boudouard Process. ACS Catal. 2015, 5, 2719-2726.

(76) Ng, M. L.; Abild-Pedersen, F.; Kaya, S.; Mbuga, F.; Ogasawara, H.; Nilsson, A. Low Barrier Carbon Induced CO Dissociation on Stepped Cu. Phys. Rev. Lett. 2015, 114, 246101. 